\title{
A QUESTÃO FUNDIÁRIA EA CONJUNTURA ATENIENSE DO GOVERNO OLIGARQUICO DE 411 A. C.
}

André Leonardo Chevitarese

Universidade Federal do Rio de Janeiro

Resumo: Este artigo analisa, através da documentação textual, a ocorrência ou não de confiscações de propriedades fundidárias em Atenas durante o governo oligárquico de 411 a. $C$.

Palavans-chave: atenas; oligarquia; questão fundiária

A História Agrária e Rural da sociedade greco-romana foi objeto de diversas pesquisas nas mais variáveis perspectivas teóricas.

Retomamos este objeto de pesquisa por múltiplas razões: primeira, nenhum fenômeno histórico, por mais que tenha sido estudado, não se esgota. 0 historiador pode e deve retomar e rever o conhecimento histórico, pois é nessa dinâmica de contestação da verdade estabelecida que concebemos a produção do saber. Segunda, a nossa proposta de pesquisa é fazer uma história rural regional num tempo histórico determinado utilizando documentos textuais e informações arqueológicas. É preciso esclarecer que a documentação arqueológica cresce constantemente $e$, através dela, se obtem novas informaçōes diferentes das que advêm da documentação textual. Só por este aspecto a retomada do tempo já é novo. Além do mais, a opção do método comparativo nos levou à prática transdisciplinar. Sendo assim, os resultados das pesquisas de clima, solo, pluviosidade, demografia, pólen, técnica agrária, ocupação do espaco, relações de parentesco, mobilidade social, conflitos sociais, comunicação fizeram com que 0 objeto de pesquisa, embora pareça para os desavisados mera repetição, na verdade é uma nova forma de fazer história.

Para este artigo preparamos uma pequena análise da documentação textual para que, em outra ocasião, possamos apresentar as diferentes informaçōes que obtivemos da arqueologia: cultura material e iconografia.

A situação bastante delicada que Atenas estava passando no plano externo - derrota militar na Sicllia, defecção de importantes póleis no interior do seu império, o apoio persa aos lacedemônios e a ocupação da Deceleia por Ágis e os aliados peloponésios - propiciou uma situação de incerteza e inseguranca quanto ao futuro imediato entre os cidadãos atenienses. É no interior desta conjuntura políticomilitar desfavorável que irá ocorrer o golpe oligárquico, denominado de governo dos Quatrocentos.

Não existe consenso entre os dois principais relatos históricos produzidos na antiguidade quanto ao ano em que este golpe ocorreu em Atenas: Tucidides (VIII. 
$48,1)$ associa ao movimento de trazer de volta Alciblades à Atenas ${ }^{1}$, isto é, em 411 a. C. , enquanto que Diodoro (XIII. 34, 2) 0 situa no período imediatamente apos a derrota militar sofrida pelos atenienses na Sicllia, portanto, em 412. Ao longo do trabalho será priorizado o relato de Tucídides, devido a quatro questões básicas:

1. Este historiador estava proximo aos acontecimentos narrados e tinha como objetivo torná-los vivos e reais.

2. 0 seu relato é infinitamente mais rico em detalhes, enquanto que 0 de Diodoro é bastante confuso, e algumas vezes, superficial. Acreditamos que este último obteve as informações através dos historiadores mais antigos.

3. 0 silêncio produzido nas duas peças aristofânicas de 411 , quanto a sátira a cidadãos atenienses politicamente proeminentes, está relacionado, como será visto, ao quadro de extrema violência descrito por Tucidides e omitido por Diodoro.

4. 0 breve relato de pseudo-Aristóteles (Constitution D'Athens. 29-33) sobre este golpe oligárquico, que apesar de trazer algumas diferencas entre a sua narrativa e a de Tucidides, se aproxima, em algumas questões, com a análise histórica proposta por este último ${ }^{2}$.

Tucídides (VIII. 47, 2) associa desde o primeiro momento a participação de Alciblados e dos homens mais influentes no processo de abolição da democracia ateniense. Percebemos que houve um apoio inicial dos marinheiros estacionados em Samos (VIII. 48, 3) ; $^{3}$ bem como do povo de Atenas (Thucydide. VIII. 54, 1; P. Aristote. Op. Cit. 29, 1; Diodorus Siculus. XIII. 34, 2 e XIII. 36, 2). Este apoio deve ser encarado, entretanto, como inicial e provisório, resultado de uma conjuntura externa desfavorável.

Os responsáveis pela condução da oligarquia recém instaurada se caracterizam por impor um estado de violência brutal contra os opositores. Este comportamento era decorrência da impunidade que havia em Atenas enquanto este regime existiu (Thucydide, VIII. 65, 1-66, 4; Stockton, 1990, p. 147).

Tucídides (VIII. 66, 5) se mostra surpreso pelo fato de que havia muitos entre os que apoiavam a oligarquia cuja adesão ninguém poderia esperar. Eram precisamente estes pseudos democratas que causaram as maiores desconfiancas entre os plethos e que prestaram aos oligarcas os maiores servicos,, garantindoIhes a seguranca. Era justamente este tipo de conduta que levou o povo a desconfiar de si mesmo.

1. Sobre o contexto histórico de Atenas durante a guerra do Peloponeso, ver: Adrados, 1983, p. 307-381.

- Todas as datas contidas neste artigo, salvo aquelas por mim especificadas, serðo antes de Cristo.

2. Sobre as diferenças entre as narrativas de Aristóteles e de Tucidides, ver: Stockton, 1990, p. 142-156.

3. Com relação à ótima acolhida dada a Alcibiades em Samos, ver: Diodorus Siculus. XIII. 41, 5-42, 1 Quanto ao exército estacionado em Samos ser hostil aos Quatrocentos, ver: Andocide. Sur Son Retour, 11 e 14. Não há dúvida que este orador está se referindo a um momento posterior àquele de Tucidides e de Diodoro. 
Numa assembléia realizada em Colonos, fora das muralhas de ásty, onde somente aqueles cidadãos com armaduras e armas poderiam seguramente participar, foram apresentadas e aceitas três propostas (Thucydide. VIII. \&, 2-3; Sinclair, 1989, p. 67) que tiveram um impacto enorme junto ao corpo clvico:

1. A extinção dos poderes de todos os magistrados em exercício;

2. A abolição dos misthol para os cargos públicos;

3. A escolha de cinco homens para a presidência: estes escolheriam cem homens e cada um dos cem escolheria três outros em adição a si mesmo.

Desta forma, com o governo dos Quatrocentos constituído, os oligarcas atenienses intensificam a mudança da forma de governo democrática pela oligárquica nas demais póleis do Império e buscam um acordo de paz com os lacedemônios (Thucydide. VIII. 64, 1 e VIII. 70, 2). É neste momento, no qual se busca a concentração sobre a situação da Ática e da sua população. Tucídides (VIII. $71,1-2)$ informa que os lacedemônios rejeitaram tentativas de acordo que foram encaminhadas pelos mensageiros dos Quatrocentos a Ágis, rei dos espartanos, que estava acampado na Deceleia. A partir desta rejeição, Tucídides observa que este rei avança com seu exército até bem perto das muralhas de Atenas.

Não deixa de ser interessante 0 fato de Agis sair da Deceleia e avançar com seu exército até bem perto das muralhas, portanto, percorrer praticamente vinte e um quilômetros sem ser importunado por ninguém. Somente quando ele chega perto das muralhas, é que os atenienses irão sair para atacá-lo. Deve ser observado que este avanço de Agis não foi acompanhado pela retirada da população da Ática rumo à ásty. É bastante significativo o fato de Tucidides não mencionar mais a existência de uma população rural na Ática. Existe, porém, uma pequena referência em Plutarco (Alcibiades. XXII, 5), onde este biografo informa que Atenas era dona apenas daquelas terras próximas das muralhas quando Alcibíades retornou a ela em $410^{4}$. Acrescentando este dado de Plutarco ao silêncio de Tucídides sobre as terras fora de Atenas, pode-se deduzir que todos os cidadãos atenienses estavam localizados perto ou dentro das muralhas da cidade e a Ática, com suas áreas cerealiferas e frutiferas, bem como as suas propriedades patrimonias rurais, destruída ou abandonada ao exército invasor. Na própria obra de Tucídides (VIII. 66, 3) existe uma afirmação que pode confirmar esta dedução, quando este historiador fala sobre a desconfiança que havia entre os aenienses durante 0 golpe oligárquico. Esta desconfiança generalizada era decorrência, segundo Tucidides, do tamanho da ásty e do fato de muitos habitantes não se conhecerem uns aos outros. 0 fato de muitos cidadãos não se conhecerem poderia ser decorrência, talvez, do contato entre individuos dos espaços urbano e rural que agora se encontrava de forma permanente na ásty.

Deve-se observar que na narrativa de Tucidides, bem como nas dos demais autores que viveram este momento ou não e que escreveram sobre ele, não é mencionado 0 confisco de propriedades rurais durante 0 governo dos Quatrocentos. A explicação para esta questão se deve, em grande parte, como 
vimos anteriormente, ao fato da própria Ática estar ocupada por um exército invasor. Devemos considerar, também, que a violência politica imposta pelos líderes desta oligarquia tinha por objetivo eliminar as possiveis lideranças democráticas que pudessem inviabilizá-la. Por fim, devemos considerar ainda um indicio que nos leva à uma terceira questão, qual seja: os apoiadores desta forma de governo deveriam ser, em sua maioria, proprietários rurais. Esta hipotese decorrente do local escolhido para a realizaçăo da assembléia onde foi aprovada a mudança na politéia ateniense. Como vimos, 0 demos de Colonos ficava fora das muralhas, sendo permitida apenas a presenca daqueles cidadăos que tinham condiçōes de se armar. Devemos supor, portanto, que estes cidadãos estavam situados na ordem sensitária de Sólon como zeugitas ou híppeis. Assim sendo, não seria uma medida aconselhável à recém instaurada oligarquia confiscar propriedades fundiárias sob qualquer pretexto, já que este tipo de ação poderia gerar um clima de insegurança e temor junto a seus apoiadores.

Existe uma interessante informação, ao longo dos acontecimentos que marcaram a chegada ao poder dos Quatrocentọs, que resume as três questōes levantadas acima. Ela está ligada ao momento em que a nau Párdos foi mandada de volta a Atenas com a noticia de que em Samos a democracia foi mantida e que as tropas atenienses estacionadas nesta ilha não apoiavam a oligarquia. Imediatamente após a sua chegada ao porto, alguns tripulantes da Páralos são presos e o restante da tripulação é tranferido para outras embarcações pelos Quatrocentos. E para este momento que as atenções devem se voltar, isto é, Queréias, um cidadăo ateniense, partidário da causa democrática, que estava a bordo da referida nau, consegue fugir e retorna a Samos. Nesta ilha, segundo Tucidides (VIII. 74, 3), ele faz um relato bastante exagerado da situação em Atenas as tropas atenienses. Apesar de um pouco extenso, é interessante citar os principais pontos contidos no relato.

[...] disse que estavam espancando todos os habitantes a pretexto de puni-los, e que não era permitido dizer uma palavra sequer contra os detentores do poder; que as mulheres e as criancas dos cidadãos estavam sendo ultrajadas e que a oligarquia pretendia confinar em Samos os parentes de todos os integrantes do exército que não fossem de sua opinião, com o intuito de executar aquelas se estes não se submetessem à sua autoridade; e acrescentou muitas outras invencionices.

Não deixa de ser curioso o fato de não ser mencionado o confisco de propriedades fundiárias, mesmo num relato bastante exagerado, por parte de Queréias.

Num momento seguinte, os Quatrocentos enviam emissários para apaziguar os soldados em Samos e, ao mesmo tempo, dar explicaçð̄es sobre a situação em Atenas. Estas explicações visavam reconciliar os atenienses de ambas as partes. Era de vital importância para a manutenção do governo dos Quatrocentos ter a frota ateniense do seu lado, principalmente pela necessidade que a polis tinha de gêneros alimentícios importados (Thucydide. VIII. 76, 4). Apesar da resistência inicial da tropa, inclusive com ameaça de morte dos emissários, estes conseguem fazer um relato. Tucidides (VIII. 86,3 ) sistematizou os pontos centrais. 
[...] disseram que os parentes dos soldados năo estavam sendo ofendidos, como Queréias relatara caluniosamente, nem sendo mal tratados, mas continuavam em seus lares, cada um de posse de seus bens.

Diferentemente do relato de Queréias, os emissários fazem questão de salientar que os parentes dos soldados continuavam de posse de seus bens. Isto pode sugerir que aquilo que Tucidides chama de outras invencionices de Queréias, poderia significar a questão da ameaça de perda dos bens, incluíndo al a propriedade fundiária, caso o cidadão ameaçado a tivesse. Não faz sentido, portanto, entender a preocupaçāo dos emissários de mostrar que existe a garantia dos bens dos cidadãos no governo dos Quatrocentos, se não houvesse esse tipo de colocação por parte do exército ateniense estacionado em Samos.

0 silêncio de Tucidides acerca da inexistência do confiscos de propriedade fundiária, bem como dos demais documentos textuais literários, não pode ser atribuído a um apoio ou concordância deste historiador ao governo dos Quatrocentos. Como já foi observado, Tucidides irá condenar este governo pelo método violento que utilizou para se manter no poder. Não faz sentido, portanto, interpretar 0 silêncio de Tucidides sobre o confisco de terras como uma omissão de sua parte, já que o confisco seria uma forma violenta de usurpação, quando ele condenava a prática de violência e assassinato por parte do governo dos Quatrocentos. Este historiador năo faz, em nenhum momento, qualquer tipo de elogio a esse tipo de governo enquanto ele esteve no poder. Em sentido oposto a essa condenação, Tucídides (VIII. 97, 2; P. Aristote. Constitution D'athenes. 33, 2) assume uma posição abertamente favorável a outra forma de oligarquia que substituiu a dos Quatrocentos em Athenas e que ficou conhecida como o governo dos Cinco Mil. Deve-se observar, portanto, que caso tivesse ocorrido confiscos de terra durante o periodo de tempo que em que os Quatrocentos exerceram o poder politico em Atenas, Tucidides ou qualquer outro autor antigo teriam deixado algum registro ou teriam feito alguma observação.

Não estamos bem informados de como ocorreu a restauração da democracia em 410. Há um vazio de informações entre a abrupta interrupção da narrativa de Tucídides e o inicio das Helênicas, quando Xenofonte já nos apresenta Trásilo, um dos IIderes da revolta de Samos, defendendo Atenas contra uma nova investida de Ágis, partindo de Deceleia em 410. Da mesma forma, pela narrativa apresentada por Diodoro, não há como saber o processo implementado pelos atenienses para derrubar a oligarquia dos Quatrocentos. Existe, apenas, uma passagem extremamente curta e superficial, na qual Diodoro (XIII. 38,1 ) afirma que os atenienses derrubaram esta forma de governo e instituiram uma politéla mais ampla para os cidadāos. 0 tradutor do texto de Diodoro, C. H. Oldfather, no entanto, afirma que se trata do governo dos Cinco Mil e, não propriamente do restabelecimento da democracia. Diodoro (XIII. 38,3 ) fala que, um pouco mais tarde, portanto, durante ou depois dos Cinco Mil assumirem o poder - pode ser, inclusive, que este governo já tivesse sido derrubado - Trasíbulo e Trásilo foram eleitos estrategos. Estes proeminentes cidadãos assumem essas funçōes em 411, segundo este historiador, e nāo em 410, como pode ser deduzido de Xenofonte. Tudo indica que o governo dos Cinco Mil teve uma duração efêmera e que a própria 
democracia tinha sido restabelecida no final de 411 , justamente quando Tucídides interrompe a sua narrativa. 0 vazio temporal e o final da obra de Tucídides e 0 início da de Xenofonte tem levado os historiadores contemporaneos a datar 0 restabelecimento da democracia de 410 . 0 relato de Diodoro, em contra-partida, năo apresenta lacuna para os anos de 411-410. Admitindo que estas questōes estejam corretas, então devemos assumir também que no momento em que Xenofonte começou a escrever a sua narrativa Atenas já havia restaurado a sua democracia.

Aristófanes, também contemporâneo do período tratado, praticamente silencia sobre o golpe oligárquico. Suas comédias Lisistrata e Tesmolórias de 411 também não fazem referências aos acontecimentos politicos ou a extrema dificuldade que Atenas estava passando no plano externo. Encontramos apenas duas referências diretas a ocupação da khora ateniense nas referidas comédias. A primeira aparece em Lisistrata ( $v$. 1145-46), quando a personagem que dá o nome à peça constata a devastação do espaço rural ateniense pelos lacedemónios e seus aliados. A segunda referência se encontra nas Tesmolorias (vv. 365-366) quando 0 Coro associa como motivo das desgraças dos atenienses os medos marchando contra a khora. Estaria implícito, nesta passagem uma possivel referência aos acordos estabelecidos entre os lacedemônios e persas na última fase da guerra do Peloponeso (Thucydide. VIII, 18; VIII, 36-37; VIII, 58). Além destes dois dados, pode-se identificar uma outra referência na comédia Lisistrata (Wv. 61-2) quando esta personagem se mostra bastante decepcionada com 0 atraso das mulheres acarnenses que, segundo a protagonista, deveriam ser as primeiras a chegar na reunião. Esta personagem pode caracterizar de forma indireta uma dupla referência: o demos de Acarnes que continua a sofrer com as invasões dos lacedemônios e seus aliados e, ao mesmo tempo, a importância dos cidadãos deste demos no fornecimento de um alto número de hóplitas a Atenas.

Estas três passagens representam ao todo seis versos em duas peças com aproximadamente 1250 versos cada uma. Não há dúvida que este silêncio produzido pelas peças aristofânicas pode significar uma preocupação do poeta em evitar assumir uma posição política diante de uma realidade bastante confusa $\mathrm{e}$ violenta, como a própria narrativa de Tucídides mostrou.

A documentação textual associa uma conjuntura externa desfavorável a Atenas bem como uma situação de desesperança entre os cidadãos atenienses como responsáveis pelo golpe oligárquico de 411. Não existe, entretanto, nenhuma informação indireta ou indicios nestes documentos que informem sobre o confisco de propriedades fundiárias durante 0 governo dos Quatrocentos. Os autores antigos informam textualmente ou se expressam através de não-ditos sobre a violência imposta pelos oligarcas aos cidadãos atenienses. Não há dúvida que a propriedade dos oligarcas era eliminar a liderança da facção ligada a causa democrática e não confiscar propriedades fundiárias.

Aestract: This article analyzes, through of the documentary sources (such as historical works, forensic speeches and literary pieces), the occurrence or not of the confiscation of land proprieties in Athens during the oligarchic government in 411 BC. 


\section{Bibliografin}

\section{Documentaçăa Textual}

ANDOCIDE. Discours. Paris: Belles Lettres, 1966.

ARISTOPHANE. Lysistrata. Paris: Belles Lettres, 1973.

DIODORUS SICULUS. The Library of History. Cambridge: Loeb, 1970.

PLUTARCO. Biografos Griegos. Madrid: Aguilar, 1973.

P. ARISTOTE. Constitution D'Athenes. Paris: Belles Lettres, 1985.

THUCYDIDE. Histoire de la Guerre du Peloponese. Paris: Ed. Garnier-Flammarion, 1966, 2 vol.

XENOPHON. Helleniques. Paris: Belles Lettres, 1973.

\section{Obras Especificas}

ADRADOS, F. R. La Democracia Ateniense. Madrid: Alianza, 1983.

FINLEY, M. I. A Polltica do Mundo Antigo. Trad. A. Cabral. Rio de Janeiro: Zahar, 1985.

MossE, C. As Instituiçס̋es Gregas. Trad. A. M. D. Diogo. Lisboa: Edições 70, 1985.

SINCLAIR, R. K. Democracy and Participation in Athens. Cambridge: Cambridge Univ. Press, 1989.

StockToN, D. The Classical Athenian Democracy. Oxford: Oxford Univ. Press, 1990. 